\title{
A history of opposing reform
}

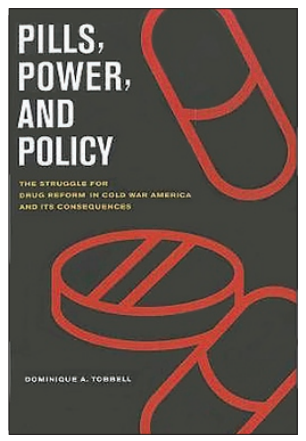

\section{Pills, Power, and Policy: The Struggle for Drug Reform in Cold War America and Its Consequences}

\section{Dominique A. Tobbell}

University of California Press, 2011

310 pp., hardcover, $\$ 65.00$

ISBN: 0520271130

\section{Reviewed by Eric G Campbell}

In Pills, Power, and Policy, Dominique A. Tobbell chronicles the political and economic history of the pharmaceutical industry in the US during the post-World War II era. Over this time, the drug industry has been widely criticized for excessively high profits, safety concerns, questionable (and sometimes illegal) marketing practices and an inability to act appropriately when faced with decisions that may have a negative impact on profits. Many leaders in research, medicine, ethics, journalism and government have argued strongly that the industry is in desperate need of reform. A key policy question in the field is why, despite a loud clamor for reform in the interest of the public, has significant reform failed to come to pass? Tobbell's book directly addresses this question, clearly describing the struggle for drug reform and presenting several strategies used by the pharmaceutical industry to thwart major reform of this industry.

The first key strategy as highlighted in this book was the formation of an extensive web of financial relationships between drug companies and individual researchers, administrators, educators and medical practitioners in the nation's leading universities and hospitals. Essentially, companies provided money to individuals in exchange for access to knowledge, skills, trainees and political influence-all of which Tobbell demonstrates were essential to further the profit motive of companies and stave off external oversight. The introduction contains a fascinating discussion of how the tobacco industry adopted this strategy and created similar networks of academics and physicians to discredit evidence regarding the linkage between smoking and cancer, as well as to fight against public criticism of the industry and the expansion of government regulation. The purpose of this analogy is not to equate the drug industry with the tobacco industry in the nature of their products but only to demonstrate that both industries employ similar tactics to fight governmental regulation.

In addition to individual relationships, the drug industry created a similar network of institutional-level alliances. Among the most important was the relationship with the American Medical Association. This alliance was based on the fear that increased regulation of the drug industry was an incremental approach toward socialized medicine, which would in turn have a negative economic impact on physicians. Other organizations that have been historically allied with the pharmaceutical industry include medical schools, teaching hospitals, patient advocacy groups and even the US Federal Drug Administration. In fact, according to Tobbell, it is hard to find a major organizational entity in the field of medicine or research that the drug industry omitted from this strategy.

The third industry strategy (which is not mentioned explicitly in this book but clearly implied) was the use of propaganda, which I define as the systematic spread of deceptive or distorted information to achieve a predetermined set of goals. For example, the industry commonly asserts that several questionable marketing practices are no longer in use. However, all one has to do is examine the list of settled claims of illegal marketing in the last decade up until now to suspect that this assertion is indeed propagandist. Another example is the effort by the industry to pass off certain types of financial relationships as educational or research related when in reality they are promotional in design and implementation. Examples of such marketing relationships include speaker bureaus, seeding trials, gifts to doctors and certain forms of continuing medical education. Some industry representatives may argue these practices, while prevalent until the early 2000s, are no longer being practiced today. However, data from 2009 show that $71 \%$ of physicians report receiving gifts from the drug industry and $9 \%$ have served on speakers bureaus within the last year. What is interesting is that while many see these practices as unethical and something to be stopped, industry proponents consider them not only appropriate, but also good business practices to be encouraged.

In the epilogue, Tobbell details how the industry employed, and in some instances modified, these strategies to fight several major US health policy reform initiatives, including the Patent Term Restoration and Price Competition Act of 1984, the Medicare Prescription Drug Improvement and Modernization Act of 2003 and the Patient Protection and Affordable Care Act of 2010. In each of these instances, the industry masterfully manipulated the political process by using the above strategies to protect the status quo in terms of regulatory policy. Tobbell points out that "strategic alliance building and politicking" by pharmaceutical companies will continue to block government regulation of their industry into the future unless there will be serious changes to our "broader political culture."

Overall, this is a well-written and scholarly addition to the literature in the field. This book should be a valuable resource for graduate students, health policy researchers, regulators and strategists who are interested in pharmaceutical policy, narrowly, or in healthcare policy, more broadly.

\section{COMPETING FINANCIAL INTERESTS}

The author declares no competing financial interests. 